\title{
THE EFFECT OF MENOPAUSE ON NADPH OXIDASE LEVELS AFTER NON- SURGICAL PERIODONTAL TREATMENTS ON PATIENTS WITH PERIODONTITIS
}

\begin{abstract}
Objectives: This study evaluated the clinical parameters [plaque index (PI), gingival index (GI), probing pocket depth (PPD), clinical attachment level (CAL)] and the levels of Nadph Oxidase (NOX-1) in gingival crevicular fluid (GCF) samples of premenopausal and post-menopausal periodontally healthy and periodontitis patients.
\end{abstract}

Materials and Methods: Study included pre-menopausal periodontitis 15, postmenopausal periodontitis 15 , pre-menopausal periodontally healthy 15 and postmenopausal periodontally healthy 15 ; a total of 60 individuals were included.

Results: Clinical periodontal evaluation indices in the 6th week after treatment were found to be statistically significantly lower than the initial values of PI, GI, PPD, CAL in the periodontitis groups $(\mathrm{p}<0.05)$. Pre-treatment baseline NOX-1 values were singificantly higher in both periodontitis groups than healthy groups $(\mathrm{p}<0.05)$. While the pre-menopausal and post-menopausal periodontitis groups before treatment had similar PI, PPD and CAL values, the GI was found to be significantly higher in the post-menopausal periodontitis group $(\mathrm{p}<0.05)$. While NOX-1 values in pre-treatment GCF samples were similar in pre-menopausal and post-menopausal periodontitis groups, NOX-1 values in the post-menopausal periodontitis group at the 6th week after treatment were found to be statistically higher than the pre-menopausal periodontitis group $(\mathrm{p}<0.05)$.

Conclusions: According to the results of our study, oxidative stress that increases with menopause may negatively affect the healing potential after periodontal treatment. Accordingly, antioxidant supplementation can be predicted with hormone replacement during this period.

Keywords: Periodontitis, Nox-1, Menopause, Oxidative Stress.

\author{
*Mahmut Kayaalt1 ${ }^{1}$ \\ Vildan Bostanc1 ${ }^{1}$ \\ iD Halef Okan Doğan ${ }^{2}$
}

ORCID IDs of the authors:

M.K. 0000-0002-6660-3053

V.B. $\quad 0000-0002-4460-301 \mathrm{X}$

H.O.D. 0000- 0001- 8738-0760

How to Cite Kayaaltı M, Bostanc1 V. The Effect of Menopause on Nadph Oxidase Levels After Non-Surgical Periodontal Treatments on Patients with Periodontitis. Cumhuriyet Dent J 2021;24:4:415-426.

*Corresponding Author:

Department of Periodontology, Faculty of Dentistry, Sivas Cumhuriyet University, Sivas, Turkey.

Phone: + $905056009538 \quad$ E-mail: mahmutkayaalti@ hotmail.com.tr 


\section{INTRODUCTION}

Periodontal disease is a chronic inflammatory disease occurring as a result of the complex interactions between the periodontal pathogen bacteria and host immune response, characterized by periodontal tissue destruction and tissue loss, in which environmental and genetic factors play a role in its etiopathogenesis and progress. ${ }^{1}$

Although the primary etiological agent in periodontal diseases is gram-negative anaerobic or facultative bacteria in microbial dental plaque, abnormal contact responses formed against such organisms and products cause periodontal tissue destruction. $^{2}$

It is reported that the chronic inflammatory state is inducted and inflammation becomes intensified due to the joining of some cytokine and hormones secreted systematically, bacteria and bacterial products to the blood circulation. ${ }^{3}$ It was determined that there was a rise in saliva, GCF and inflammatory mediators in serum due to the periodontal destruction in individuals with periodontitis. ${ }^{4}$

Environmental, genetic and acquired factors may change the host response that forms against pathogen and modify the amount of destruction in periodontal tissues. $^{5}$

There are two mechanisms responsible for periodontal tissue destruction. The first mechanism is the direct effect of the bacteria through the toxic materials that it produced, proteases and endotoxins; the second mechanism is the indirect effect mediated the inflammatory mediators produced by the host. ${ }^{6}$ The difference of inflammatory response for every individual causes difference in the rate of progression and severity of the destruction. ${ }^{4}$

It is shown that oxidative stress plays a major role in many diseases such as obesity, periodontitis, rheumatoid arthritis, diabetes mellitus, cardiovascular diseases, hemolytic anemia, systemic lupus erythematosus, multiple sclerosis, Behcet disease and Guillain-Barre syndrome. ${ }^{7-13}$
NOX enzymes are proteins linked to the membrane, and their main function is transferring electrons from the plasma membrane to molecular oxygen. $\mathrm{O}_{2^{-}}$is formed by the transfer of the electrons to molecular oxygen. It causes the formation of $\mathrm{O}_{2^{-}}, \mathrm{H}_{2} \mathrm{O}_{2}$, and $\mathrm{OH}$ radicals and leads to reactive oxygen species (ROS). ${ }^{14,15}$

The principal center of the ROS formation in the cell occurs in the plasma membrane and mitochondrion. Cytokines activate NOX through growth factors and hormones. The activated NOX causes $\mathrm{O}_{2}$ - production. One to two percent of the electrons transferred in a manner to follow each other in the electron transfer chain is directly transferred to molecular oxygen through leakage, resulting in the production of $\mathrm{O}_{2}$ - radical. ${ }^{16}$

It is determined that NOX enzymes are essential in the immune system, protein translation, cellular signal transmission and gene expression, furthermore in the modulation of the redox-sensitive signal pathway related to functions such as growth, differentiation, migration and proliferation of cells. ${ }^{15}$

The protein regulating NOX enzyme activity comprises two sub-units and four cytosolic proteins bound to the membrane. Two cytochrome heterodimer components (gp91phox and p22phox) bound to membrane and four cytosolic components (p47phox, p67phox, p40phox) and RAC2 activate NOX to produce $\mathrm{H}_{2} \mathrm{O}_{2}$. Activation starts with combining the membrane-located gp91phox and p22phox of NOX at the rate of 1:1, and cytochrome b588 occurs. This activation combines the cytosolic components of the NOX enzyme ( $\mathrm{p} 47, \mathrm{p} 67, \mathrm{p} 40$ ) with cytochrome b558 and the joining of GTP- protein to this complex as an activator. Lack of any of the four components of NOX (gp91,p22, p47, p67) and GTP binding protein (Rac2) terminates NOX activity. ${ }^{17}$

Some NOX enzymes are located higher in some organs and tissues. For example, NOX-1 is present in the colon, NOX-2 is present in phagocytes, NOX-3 is present in the inner ear, NOX-4 is present in the kidney, NOX-5 is present in testicles lymphoid tissues, and DUOX-1 and DUOX-2 are present in thyroid. ${ }^{18}$ 
NOX-1 is expressed in endothelial and smooth muscle and cells. Many studies showed that NOX-1 is localized in cell membranes, especially in the plasma membrane. ${ }^{15}$ NOX-1 activity requires its sub-units being p22phox, NoxO1 (or p47phox), NoxA1 and GTPase Rac. It is shown that NOX-1 dependent ROS production has a significant role in cell signaling, cell growth, angiogenesis and cell mobility. ${ }^{19}$

NOX-1 mediates vascular endothelial growth factor (VEGF) and matrix metalloproteinase (MMPS) expressions; it can increase ROS formation and support NOX-1 angiogenesis and tumorigenesis. ${ }^{20}$ Furthermore NOX-1 plays a role in cell proliferation, emerging and development of angiogenesis and hepatic fibrosis. ${ }^{21}$

It is shown that Nox-1 / Nox-2 plays a role in developing endothelial dysfunction, hypertension, and inflammation. ${ }^{22,23}$ The pro-atherogenic roles of NOX-1, NOX-2 have emerged, and it was determined that the most significant sub-unit is p47phox. ${ }^{24}$

Neutrophils and monocytes show antibacterial features with cooperating enzymatic (non-dependent to oxygen) and non-enzymatic (oxygen-dependent) mechanisms in periodontal defense mechanisms. Oxygen-dependent, i.e., Non-enzymatic mechanism, is related to nonmitochondrial oxidative burst and increased ROS production; and causes tissue damage in host besides its antimicrobial effect against pathogens. The normally inactive NOX enzyme in the plasma membrane of neutrophils is activated by this mechanism and forms $\mathrm{O}_{2-}$ and is used against bacteria in the phagosome. The formed $\mathrm{O}_{2}$ - forms $\mathrm{H}_{2} \mathrm{O}_{2}$ is automatically dismutated at a low $\mathrm{pH}$ level in the phagosome. This phenomenon occurs as intense radical accumulation within phagosome is named as "respiratory burst" or "oxidative burst." This process is detrimental to host cells besides its antimicrobial contribution. ${ }^{25}$

Various pro-inflammatory cytokines (TNF- $\alpha$, IL-8, IL-1, IL-6), growth factors and lipopolysaccharides exhibit triggering features for the respiratory burst of neutrophils. ROS, which is formed through these interactions, leads to proteoglycans in periodontal tissues, lysis in epithelial cells, osteoclast activation, carbohydrate, lipid and protein catabolism and causes periodontal destruction. ${ }^{26}$

Tissue destruction occurs through the stimulation of cytokines through NF- $\mathrm{BB}$ activation; release of pro-inflammatory cytokines such as IL-1, IL-6, TNF- $\alpha$ and prostaglandin E2 generation through lipid peroxidation and $\mathrm{O}_{2}-$. Furthermore, ROS activity plays a role in an inflammatory state caused by periodontal diseases on other organs at the systemic level. ${ }^{27}$

According to the World Health Organization (WHO) definition, menopause is the permanent termination of menstruation as a result of the loss of ovary activity. ${ }^{28}$

It is stated that changes in female gender hormones may affect the severity of periodontal diseases. ${ }^{29} \mathrm{~A}$ decrease in the amount of estrogen occurring by menopause causes osteoporosis systematically and in alveolar bone, increase in the CAL, and increase in the inflammation in gingival tissues. ${ }^{30}$

Besides the systematic changes in menopause, also intra-oral changes may occur. The flow rate of the saliva that secreted by submandibular and sublingual salivary glands, decreased. The incidence of decay and formation of periodontitis increase due to the decrease in the number of salivary glands. Deterioration of flavor, senile atrophic gingivitis, menopausal gingivostomatitis can also be seen in the menopause period. ${ }^{31}$ Changes such as puberta gingivitis, pregnancy gingivitis are seen in situations such as puberta and pregnancy in which female gender hormones change, and it is mentioned that periodontal situation is frequently affected negatively. ${ }^{29}$ It is stated that gingivitis in periods such as pregnancy and puberta may be due to vasodilatation, increase in vascular permeability and increase in mast cells around vessels caused by estrogen on vascular system. ${ }^{32}$

Estrogen decreases the formation of inflammatory cytokines essential in osteoclastic activation, and the lack of estrogen causes a more 
gingival severe inflammation and osteonecrosis during periodontitis. ${ }^{30}$

Furthermorethe osteoporosis table, alveolar osteonecrosis occurs systemically in the menopause period. Osteonecrosis is seen most dense in the first year following menopause and increases its rate in a subsequent process. The history of osteoporosis in the family, premature menopause, lacking physical activity, vitamin D and calcium deficiency, old age, regular smoking and drinking alcohol may increase the risk of osteoporosis. $^{33,34}$

Oral atrophic mucosa is frequently seen in females in menopause; burning mouth syndrome can also be seen as a more severe symptom. Burning mouth syndrome is characterized by automatically starting burning and pain. ${ }^{35}$ Tongue, lips, palate, tooth-supporting tissues and gingiva are also affected. Dense burning and pain are present, although no underlying pathological lesion is seen. Moreover, bad taste, desert mouth, difficulty in swallowing may also be experienced. Estrogen supplement psychological support and use of tricyclic antidepressant are present in its treatment. $^{36}$

No study concerning how menopause affected biochemical marker levels related to NOX-1 among oxidative stress enzymes in females with periodontitis has been seen in the literature search. Therefore we aimed to review the relationship between the NOX-1 enzyme levels in females in the premenopausal and postmenopausal period and some clinical periodontal parameters showing the periodontal health conditions.

\section{MATERIALS AND METHODS}

Approval was obtained from Cumhuriyet University, School of Medicine Researches Ethical Committee on 17.12.2019 with decision no. 2019-12/05 for the study. Systemically healthy 30 individuals with periodontitis and 30 periodontally healthy individuals admitting to Cumhuriyet University Faculty of Dentistry Department of Periodontology Clinic between 2019-2020 participated in our research. The patients signed a voluntary consent form showing that they participated in the study voluntarily. The current classification, named as 2017 Classification of Periodontal and Peri-implant Diseases and Conditions, was used to describe the study groups to be studied in the research.

\section{Study Groups}

GROUP PRP: Pre-menopause periodontitis patients who did not enter into menopause (15 individuals)

GROUP POP: Post-menopause periodontitis patients who entered into menopause (15 individuals)

GROUP PRH: Pre-menopause periodontally healthy individuals who did not enter into menopause (15 individuals)

GROUP POH: Post-menopause periodontally healthy patients who entered into menopause (15 individuals)

\section{GROUP PRP}

Periodontitis patients who stated that they did not enter into menopause in their verbal medical history, with probing depth (PPD) of $\geq 4$ and $<7$ at least at 2 non-adjacent teeth, with bleeding in probing, inflammation symptoms, bone loss extending to the middle of the root or apical trio.

Stage III periodontitis, degree B.

\section{Group POP}

Periodontitis patients stating in the verbal medical history taken that a time longer than 1 year has passed as of the starting of menopause, PPD of $\geq 4$ and $<7$ at least at 2 non-adjacent teeth, with bleeding in probing, inflammation symptoms, bone loss extending to the middle of the root or apical trio.

Stage III periodontitis, degree B.

\section{Group PRH}

Periodontitis patients who stated that they did not enter into menopause in their verbal medical history; who are periodontally healthy with the whole mouth bleeding score below $10 \%$, with an PPD not exceeding $3 \mathrm{~mm}$ in teeth, with Decreased or Non-Deteriorated Periodontal Health. 


\section{Group POH}

Individuals stating in the verbal medical history taken that a time longer than 1 year has passed as of the onset of menopause, who are periodontally healthy with the whole mouth bleeding score below $10 \%$, with an PPD not exceeding $3 \mathrm{~mm}$ in teeth, with Decreased or Non-Deteriorated Periodontal Health.

In periodontitis patient groups 2 non-adjacent teeth with $\mathrm{PPD} \geq 4,33 \%$ periodontal bone loss was determined by sampling GCF before the initial periodontal treatment. The GCF samples were taken from any 2 teeth among the maxilla incisor teeth on each half jaw in periodontally healthy individuals.

\section{Clinical Evaluation}

A single researcher (M.K) carried out clinical evaluation indices, GI, PI, PPD and CAL analyses in patients were carried out by a single researcher (M.K) throughout the research.

Periodontal clinical treatment including PPD, CAL, PI and GI measurements in periodontitis patients was carried out initially and in the 6th week.

The initial periodontal treatment, including subgingival curettage and root planning processes by Gracey curettes (Hu-Friedly, Chicago, IL, USA) following oral hygiene training and scaling and periodontal treatment of each patient was completed within 14 days.

All clinical periodontal measurements and GCF samples were taken from the individuals in periodontitis patient groups 2 times in total (before periodontal treatment, 6th week) throughout the study; they were taken only once from the individuals in the control group.(Figure 1)

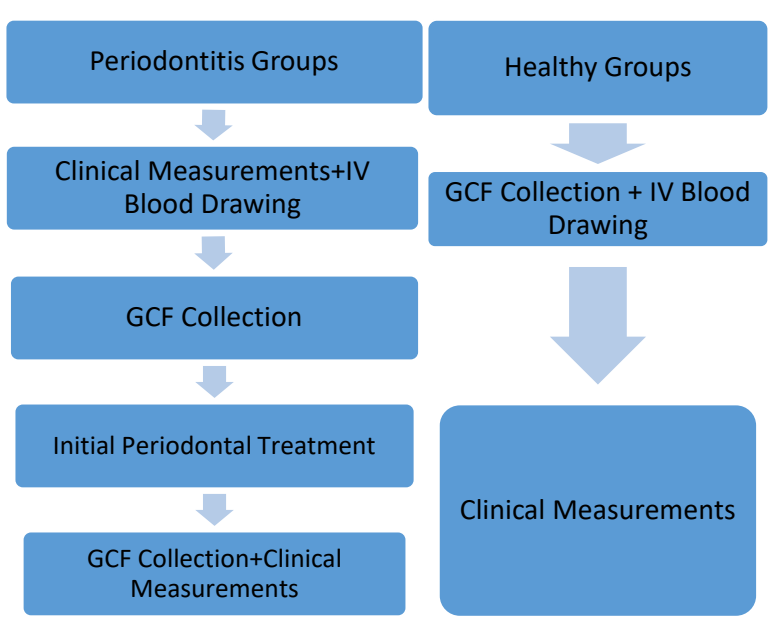

Figure 1: Study Plan Work Flow Chart

\section{Collection of Samples}

The patients were asked whether they entered menopause or not, and the information on the onset of menopause in the patients stating that they entered menopause was obtained. Approximately $15 \mathrm{ml}$ venous blood sample was taken from patients in order to establish a final diagnosis. The samples were centrifuged for 10 minutes at $15000 \mathrm{x}$ g speed to decompose serum, and then the serum was decomposed to eppendorf tubes. Serum samples were kept at - 80 degrees until the day of analysis. The measurements were in the central laboratory of Cumhuriyet University School of Medicine Biochemical Department on the day of analysis. Two patients stated that they entered menopause in their medical histories, with FSH hormone levels at $40-60 \mathrm{IU} / \mathrm{L}$ and E2 levels at $20-22 \mu \mathrm{g} / \mathrm{ml}$ were removed from postmenopausal patient groups as they might be in the perimenopausal period. 5 individuals among the patients stating that they did not enter menopause were removed from the study group because they might be in the perimenopausal period as their serum E2 levels were at $20-22$ $\mu \mathrm{g} / \mathrm{ml}$ and their FSH levels were at 40-60 IU/L.

The GCF samples were taken from periodontitis patients a week following their clinical measurements and in the morning (09:0011:00) in periodontally healthy patients using Periopaper (OraFlow Inc, Amityville, NY, USA). The PPD 4-6 mm-areas were preferred at the anterior maxilla area to mitigate the risk of slobbering in the GCF collection. Periopapers were intrasulcularly positioned in the gingival crevice. It was held for 30 seconds in the crevice 
to establish standardization in each sample, and GCF was retaken in periopapers contaminated by blood. Periopapers were put into eppendorf tubes and were held at $-80^{\circ} \mathrm{C}$ until the day of analysis.

\section{Laboratory Studies}

The GCF samples collected were used by NOX-1 ELISA kits as per the suggestions of the manufacturer company (Fine Test, Wuhan, China) in Cumhuriyet University School of Medicine Biochemical Department.
Statistical Analysis of Data

Descriptive statistics, regular distribution analysis (Kolmogorov-Simirnov), Dependent groups t-test, Independent groups t-test, Pearson correlation analysis were conducted using IBM SPSS 22.0 suit.

\section{RESULTS}

15 pre-menopause periodontitis patients (Group PRP), periodontally healthy 15 pre-menopause patients (Group PRH), 15 post-menopause periodontitis patients (Group POP), periodontally healthy 15 post-menopause patients (Group $\mathrm{POH}$ ) were included in the study (Table 1).

Table 1: Demographic situations of the individuals participating in the study

\begin{tabular}{lcccc}
\hline $\begin{array}{l}\text { Patients } \\
\text { Groups }\end{array}$ & $\begin{array}{c}\text { GRUP PRP } \\
\mathrm{n}: 12\end{array}$ & $\begin{array}{c}\text { GRUP PRH } \\
\mathrm{n}: 13\end{array}$ & $\begin{array}{c}\text { GRUP POP } \\
\mathrm{n}: 14\end{array}$ & $\begin{array}{c}\text { GRUP POH } \\
\mathrm{n}: 14\end{array}$ \\
\hline Age & $43.30( \pm 2.73)$ & $42.43( \pm 2.30)$ & $48.80( \pm 1.26)$ & $49.88( \pm 1.37)$ \\
Age intervals & $40-49$ & $40-48$ & $48-52$ & $48-53$ \\
$\begin{array}{l}\text { Menopause(years } \\
\text { ago) }\end{array}$ & - & - & -2.72 & -2.85 \\
\hline
\end{tabular}

\section{Clinical Findings}

The difference between the pre-treatment PI, PPD and CAL values PRP and POP groups was not statistically significant $(\mathrm{p}>0.05)$. However, GI values are higher in a POP group than PRP group, and the difference was statistically significant $(\mathrm{p}<0.05)$

The difference in PRP and POP groups in PI, GI, PPD, CAL values in the post-treatment 6thweek results was not statistically significant ( $>0.05$ ).

Pre-treatment initial PI, GI, PPD values of PRP and PRH group were higher in the PRP group than PRH group, and the difference was statistically significant $(\mathrm{p}<0.05)$
Pre-treatment initial PI, GI, PPD values of $\mathrm{POP}$ and $\mathrm{POH}$ group were higher in a POP group than $\mathrm{POH}$ group, and the difference was statistically significant $(\mathrm{p}<0.05)$.

Upon comparing the pre-treatment and posttreatment 6th-week results of PRP group patients PI, GI, PPD, CAL pre-treatment values were higher than the post-treatment 6th-week values, and the difference was found statistically significant $(\mathrm{p}<0.05)$.

Upon the comparison the pre-treatment and posttreatment 6th-week results of POP group patients PI, GI, PPD, CAL pre-treatment values were higher than post-treatment 6th-week values, and the difference was found statistically significant $(\mathrm{p}<0.05)$. (Table 2) 
Table 2: Clinical and Laboratory Results

\begin{tabular}{|c|c|c|c|c|c|c|}
\hline Parameters & $\begin{array}{l}\text { PRP } \\
\text { Baseline }\end{array}$ & 6th Week & $\begin{array}{l}\text { POP } \\
\text { Baseline }\end{array}$ & 6th Week & $\begin{array}{l}\text { PRH } \\
\text { Baseline }\end{array}$ & $\begin{array}{l}\text { POH } \\
\text { Baseline }\end{array}$ \\
\hline Plaque Index & $1.91 \pm 0.05^{b}$ & $1.22 \pm 0.20^{\mathrm{a}}$ & $1.96 \pm 0.11^{\mathrm{c}}$ & $1.16 \pm 0.08^{a}$ & $0.81 \pm 0.09$ & $0.86 \pm 0.11$ \\
\hline $\begin{array}{l}\text { Gingival } \\
\text { Index }\end{array}$ & $1.97 \pm 0.09^{b}$ & $1.11 \pm 0.11^{\mathrm{a}}$ & $2.11 \pm 0.09^{\mathrm{c}, \mathrm{d}}$ & $1.12 \pm 0.08^{\mathrm{a}}$ & $0.68 \pm 0.07$ & $0.85 \pm 0.08$ \\
\hline $\begin{array}{l}\text { Probing } \\
\text { Pocket } \\
\text { Depth }\end{array}$ & $4.69 \pm 0.41^{b}$ & $3.54 \pm 0.15^{\mathrm{a}}$ & $4.83 \pm 0.28^{c}$ & $3.68 \pm 0.27^{\mathrm{a}}$ & $2.36 \pm 0.13$ & $2.60 \pm 0.08$ \\
\hline $\begin{array}{l}\text { Clinical } \\
\text { Attachment } \\
\text { Level }\end{array}$ & $6.69 \pm 0.74^{b}$ & $5.28 \pm 0.57^{\mathrm{a}}$ & $6.39 \pm 0.49^{c}$ & $5.18 \pm 0.43^{\mathrm{a}}$ & -0 & -0 \\
\hline NOX-1 & $7.19 \pm 2.94^{b}$ & $1.89 \pm 1.58^{\mathrm{a}}$ & $8.12 \pm 2.54^{\mathrm{c}}$ & $3.78 \pm 2.24^{\mathrm{a}, \mathrm{d}}$ & $2.73 \pm 1.21$ & $2.75 \pm 1.17$ \\
\hline
\end{tabular}

significantly different from periodontitis groups baseline $(\mathrm{p}<0.05)$

bignificantly different from the PRHgroup. $(\mathrm{p}<0.05)$

${ }^{c}$ significantly different from the POH group. $(\mathrm{p}<0.05)$

${ }^{\mathrm{d}}$ significantly different from the PRP group. $(\mathrm{p}<0.05)$

\section{Laboratory Findings}

Upon comparing the periodontal pre-treatment and post-treatment NOX-1 values in PRP and POP groups, including periodontitis patients, pretreatment initial values were higher than the 6thweek results, and the difference was statistically significant $(\mathrm{p}<0.05)$.

Upon comparing pre-treatment NOX-1 values of the PRP and POP groups, the initial NOX-1 values of the POP group were higher; however, the difference was not found statistically significant $(\mathrm{p}>0.05)$.

The NOX-1 values according to the posttreatment 6th-week results were found higher in POP group compared to PRP group and the difference was statistically significant $(\mathrm{p}<0.05)$.

The pre-treatment initial NOX-1 values of the PRP and PRH group were found higher in the PRP group than PRH group, and the difference was statistically significant $(\mathrm{p}<0.05)$

The pre-treatment initial NOX-1 values of the POP and $\mathrm{POH}$ group were higher in the POP group than the $\mathrm{POH}$ group, and the difference was statistically significant $(\mathrm{p}<0.05)$.

The pre-treatment NOX-1 values of periodontitis patients correlated to the pretreatment initial NOX-1 values PI, GI and PPD values in all PRP and POP group patients in the correlation analysis $(\mathrm{p}<0.05)$.
The PI was found correlated to the GI and PPD $(\mathrm{p}<0.05)$.

The GI was found correlated to PPD $(p<0.05)$.

The NOX-1 values of the post-treatment 6thweek result in PRP and POP patient groups correlated to the 6th week PI and GI values $(\mathrm{p}<0.05)$.

The post-treatment 6th-week values correlated to the PRP and POP patient groups $(\mathrm{p}<0.05)$. (Table 2)

\section{DISCUSSION}

It was stated that the analysis of the oxidative stress products was complex due to the short halflife of $\left(\mathrm{O}_{2^{-}}, \mathrm{H}_{2} \mathrm{O}_{2}, \mathrm{OH}-\right)$ them and their replacement with the oxidative stress enzymes in the pathogenesis of periodontal diseases advantageous method. ${ }^{37}$ We preferred NOX-1 member of the NOX family among the oxidative stress mechanism enzymes, which plays a role in inflammation development.

In our study, the NOX-1 enzyme among the oxidative stress markers was found higher in both the pre-menopause periodontitis and postmenopause periodontitis groups than the periodontally healthy groups $(\mathrm{p}<0.05)$. When examined current literature there are a lot study proving that oxidative stress markers are higher in the patients with periodontitis than the periodontally healthy patients. ${ }^{38-41}$ Our study 
results comply with the studies showing that the oxidative stress products are higher in the patients with periodontitis than the periodontally healthy patients. $^{38-41}$

Upon comparison of the pre-treatment and post-treatment 6th-week NOX-1 levels of our PRP and POP group patients among periodontitis group patients, it was seen that the post-treatment NOX-1 levels significantly decreased in both groups $(\mathrm{p}<0.05)$. Upon reviewing the literature, the clinical studies evaluating the pre-treatment and post-treatment period reveal that the initial periodontal treatment decreased the oxidative stress levels in periodontitis patients. ${ }^{39,42,43}$ The decreasing oxidative stress level in the posttreatment periodontitis patients in our study complies with similar studies in the literature. . $^{39,42,43}$

Any studies using the NOX-1 enzyme could not be found among the studies in the literature showing the relationship between periodontitis and oxidative stress. Many studies worked NO, malondialdehyde (MDA), lipid peroxidation level, and total antioxidant capacity as oxidative stress markers. The oxidative stress markers evaluated in these studies were found higher in periodontitis groups than the healthy groups..$^{38,39,41}$

Tsai et al. ${ }^{39}$ found lipid peroxidation levels higher in the periodontitis group than the healthy group in the study conducted on the saliva and gingival crevicular fluid samples taken from periodontitis periodontally healthy patients. Furthermore, they found glutathione level, an antioxidant enzyme, lower in the group with periodontitis than in the healthy group. In Accordance with the healing of periodonal tissues, decreases in periodontal parameters (PI, GI, PPD, CAL) were determined. ${ }^{39}$ The decrease in the oxidative stress level compared to the posttreatment initial values and the post-treatment improvement in the clinical parameters PI, PPD, GI, CAL values are similar to our results.

Batista et $a l .{ }^{44}$ reported a positive correlation between the PI, GI, and nitric oxide synthase (INOS) expression degree in the study conducted. As a result of these studies, it was concluded that
INOS enzyme level might be a marker showing the periodontal disease activity ${ }^{44}$. In our study, pre-treatment and post-treatment NOX-1 levels were found correlated to PI and GI. Our study results have similarities with the study conducted by Batista $e t$ al.

There are various techniques for sampling GCF, which can be preferred following the result of the study, and each technique has its advantage and disadvantage. GCF sampling was conducted according to the shallow intracrevice method Rudin et al. $^{45}$ using standard paper strips to prevent irritation. The sampling time was determined as 30 seconds, as it is in many studies, to prevent the bleeding and irritation caused by the paper strips and provide a standardization. ${ }^{46}$ GCF is among the most frequently used methods as it includes host-caused enzymes playing a role in the pathogenesis of periodontitis, tissue destruction products and inflammatory markers. ${ }^{47}$

There are various techniques in which the gingival crevice measurements are conducted 1 week before ${ }^{48}$, and 2 weeks before GCF sampling $^{49}$ or after GCF sampling ${ }^{49}$ with the concern that measuring periodontal crevice depth with periodontal drilling may cause irritation and change GCF amount. In our study, GCF sampling from the sampling area was conducted a week after periodontal drilling to minimize the irritation.

A typical ideal GCF collection time is not available in all studies. Sampling times were applied in various time ranges such as $3 \mathrm{sec}$., 5 sec., 15 sec., 20 sec., 25 sec., 30 sec., 1 min., 90 sec., 2 mins., and 3 mins in the literature. However, the general opinion is that extending the sampling time increases the mechanical irritation risk. ${ }^{50} 30$ seconds GCF collection method was preferred in our study.

Many clinical studies were conducted concerning periodontitis, menopause and osteoporosis. Menopause, postmenopausal hormone treatment, estrogen level and periodontitis relation, its impact on the osteoporosis and periodontium, changes in GCF 
are the most studied subjects in studies concerning menopausal period. ${ }^{51-53}$

The periodontal effects of the hormones in females are tracked in periods such as pregnancy, puberta and menopause in which such changes are observed. ${ }^{54}$ Periodontal tissues including receptors belonging to gender hormones. ${ }^{55}$

Studies show that the decreases in menopause and estrogen levels affect the host response and may increase the damage in the periodontal tissues by causing an increase in response to the local irritants. ${ }^{56,57}$

The studies indicate that the decrease in the postmenopausal estrogen levels may be bound to cytokines such as interleukin-1, IL-6, IL-8, IL-10, TNF- $\alpha$. This increase activates the mature osteoclasts and causes systemic and alveolar bone loss by unbalancing bone formation and destruction. $^{58}$

The decrease of estrogen level through the menopausal period increases the estrogen receptor activity in osteoclasts and decreases the receptor activity in osteoblasts. ${ }^{55}$

According to the results of our study, pretreatment oxidative stress enzyme NOX-1 levels of the Group PRP and Group POP patients were not statistically different; their post-treatment 6th week NOX-1 levels were observed as statistically higher in Group POP than Group PRP $(\mathrm{p}<0.05)$. Those results suggest the effect of estrogen levels decreasing after menopause. It supports the results of the studies reporting that estrogen decreases the ROS, contributes to the antioxidant defense system, and compresses the release of cytokines.

Baltacioğlu et $a .^{59}$ found that the patients serum and GCF total antioxidant capacity levels were higher in the pre-menopause group than in the post-menopause group in the studies they conducted on pre-menopause and post-menopause periodontitis patients and healthy patients. The total antioxidant capacity was found the most in the pre-menopause healthy group and the least in the post-menopause chronic periodontitis group. ${ }^{59}$ When the impact of the antioxidant enzymes over the ROS is considered, the NOX-1 enzyme levels, which are significantly higher in the patients in the post-treatment postmenopausal period than in the pre-menopause group, can be related to the decrease of the protective role of the total antioxidant capacity, which decreases following menopause. Furthermore, the total antioxidant capacity found more in the healthy group by Baltacıoğlu et al. may explain that NOX-1 levels in the healthy groups, which we found in our study results, were significantly lower than the levels in the periodontitis groups.

PI, GI, PPD and CAL values of the group PRP and group POP patients in the 6th week after the treatment did not show statistical difference according to the results of our study ( $p>0.05$ ). Upon reviewing the literature, it can be seen that studies are showing that the PI, GI and CAL values in the postmenopausal patients were higher compared to the premenopausal patients ${ }^{30,52,60}$ or finding the values of the premenopausal and postmenopausal similar. ${ }^{61-63}$

It was shown that estrogens decreased ROS production and therefore prevented oxidative stress formation. ${ }^{64}$ It is considered that the antioxidant contribution of estrogen arises from its stimulating effect on the natural antioxidant enzymes. ${ }^{65}$

\section{CONCLUSIONS}

NOX-1 enzyme levels were significantly higher in the post-treatment 6th-week postmenopausal periodontitis group than in the premenopausal periodontitis group $(\mathrm{p}<0.05)$. We can say that the antioxidant role of the estrogen decreases, and the postmenopausal oxidative stress increases upon the decreasing estrogen following menopause.

No other study could be found concerning the evaluation of the effect of menopause on the preand post-periodontal treatment NOX-1 levels of the females who entered/did not enter into menopause. Concerning the matter, the clinical researches to be conducted with more participants in the periodontitis groups in which periodontitis is present in various severity may enable a better understanding of the effect of oxidative stress enzyme NOX-1 and menopause on the periodontitis pathogenesis. 


\section{ACKNOWLEDGMENTS}

This study was supported by the Cumhuriyet University Scientific Research Project (Project Number: Dis-248).

\section{CONFLICT OF INTEREST}

The authors declare that they have no competing interests.

\section{REFERENCES}

1. Kinane DF, Stathopoulou PG, Papapanou PN. Periodontal diseases. Nat Rev Dis Prim. 2017;3:17038.

2. Lamster IB, Novak MJ. Host mediators in gingival crevicular fluid: implications for the pathogenesis of periodontal disease. Crit Rev oral Biol Med an Off Publ Am Assoc Oral Biol. 1992;3(1-2):31-60.

3. Van Dyke TE. The management of inflammation in periodontal disease. $J$ Periodontol. 2008;79(8 Suppl):1601-1608.

4. Kinane DF. Causation and pathogenesis of periodontal disease. Periodontol 2000. 2001;25:8-20.

5. Loesche WJ, Grossman NS. Periodontal disease as a specific, albeit chronic, infection: diagnosis and treatment. Clin Microbiol Rev. 2001;14(4):727-752, table of contents. doi:10.1128/CMR.14.4.727-752.2001

6. Kornman KS. Mapping the pathogenesis of periodontitis: a new look. J Periodontol. 2008;79(8 Suppl):1560-1568. doi:10.1902/jop.2008.080213

7. Harzallah $\mathrm{O}$, Kerkeni A, Baati $\mathrm{T}$, Mahjoub $\mathrm{S}$. Oxidative stress: correlation with Behçet's disease duration, activity and severity. Eur J Intern Med. 2008;19(7):541-547. doi:10.1016/j.ejim.2008.08.001

8. Shah D, Mahajan N, Sah S, Nath SK, Paudyal B. Oxidative stress and its biomarkers in systemic lupus erythematosus. J Biomed Sci. 2014;21(1):23.

9. Suzuki K, Ito Y, Ochiai J, et al. Relationship between obesity and serum markers of oxidative stress and inflammation in Japanese. Asian Pac J Cancer Prev. 2003;4(3):259-266. http://europepmc.org/abstract/MED/ 14507248

10. Wang Y, Andrukhov O, Rausch-Fan X. Oxidative Stress and Antioxidant System in Periodontitis. Front Physiol. 2017;8.

11. Vasanthi P, Nalini G, Rajasekhar G. Status of oxidative stress in rheumatoid arthritis. Int $J$ Rheum Dis. 2009;12(1):29-33.

12. Yang H, Jin X, Kei Lam CW, Yan S-K. Oxidative stress and diabetes mellitus. Clin Chem Lab Med. 2011;49(11):1773-1782.
13. Senoner T, Dichtl W. Oxidative Stress in Cardiovascular Diseases: Still a Therapeutic Target? Nutrients. 2019;11(9):2090.

14. Dupuy C, Ohayon R, Valent A, Noël-Hudson MS, Dème D, Virion A. Purification of a novel flavoprotein involved in the thyroid NADPH oxidase. Cloning of the porcine and human cdnas. $J$ Biol Chem. 1999;274(52):37265-37269.

15. Bedard K, Krause K-H. The NOX family of ROSgenerating NADPH oxidases: physiology and pathophysiology. Physiol Rev. 2007;87(1):245-313. doi:10.1152/physrev.00044.2005

16. Daffu G, del Pozo CH, O'Shea KM, Ananthakrishnan R, Ramasamy R, Schmidt AM. Radical roles for RAGE in the pathogenesis of oxidative stress in cardiovascular diseases and beyond. Int J Mol Sci. 2013;14(10):19891-19910.

17. Azumi $\mathrm{H}$, Inoue $\mathrm{N}$, Ohashi $\mathrm{Y}$, et al. Superoxide generation in directional coronary atherectomy specimens of patients with angina pectoris: important role of $\mathrm{NAD}(\mathrm{P}) \mathrm{H}$ oxidase. Arterioscler Thromb Vasc Biol. 2002;22(11):1838-1844.

18. Gavazzi G, Deffert C, Trocme C, Schäppi M, Herrmann FR, Krause K-H. NOX1 deficiency protects from aortic dissection in response to angiotensin II. Hypertens (Dallas, Tex 1979). 2007;50(1):189-196.

19. Arbiser JL, Petros J, Klafter R, et al. Reactive oxygen generated by Nox1 triggers the angiogenic switch. Proc Natl Acad Sci U S A. 2002;99(2):715-720.

20. Thum T, Borlak J. Mechanistic role of cytochrome P450 monooxygenases in oxidized low-density lipoprotein-induced vascular injury: therapy through LOX-1 receptor antagonism? Circ Res. 2004;94(1):e113.

21. Paik Y-H, Iwaisako $\mathrm{K}$, Seki $\mathrm{E}$, et al. The nicotinamide adenine dinucleotide phosphate oxidase (NOX) homologues NOX1 and NOX2/gp91(phox) mediate hepatic fibrosis in mice. Hepatology. 2011;53(5):1730-1741.

22. Datla SR, Griendling KK. Reactive oxygen species, NADPH oxidases, and hypertension. Hypertens (Dallas, Tex 1979). 2010;56(3):325-330.

23. Montezano AC, Touyz RM. Reactive oxygen species and endothelial function--role of nitric oxide synthase uncoupling and Nox family nicotinamide adenine dinucleotide phosphate oxidases. Basic Clin Pharmacol Toxicol. 2012;110(1):87-94.

24. Dikalov SI, Dikalova AE, Bikineyeva AT, Schmidt 
HHHW, Harrison DG, Griendling KK. Distinct roles of Nox1 and Nox4 in basal and angiotensin II-stimulated superoxide and hydrogen peroxide production. Free Radic Biol Med. 2008;45(9):1340-1351.

25. Battino $M$, Bullon $P$, Wilson $M$, Newman $H$. Oxidative injury and inflammatory periodontal diseases: the challenge of anti-oxidants to free radicals and reactive oxygen species. Crit Rev oral Biol Med an Off Publ Am Assoc Oral Biol. 1999;10(4):458-476.

26. Libermann TA, Baltimore D. Activation of interleukin-6 gene expression through the NF-kappa B transcription factor. Mol Cell Biol. 1990;10(5):23272334.

27. Chapple ILC. Oxidative stress, nutrition and neutrogenomics in periodontal health and disease. Int $J$ Dent Hyg. 2006;4 Suppl 1:12-15.

28. Takahashi TA, Johnson KM. Menopause. Med Clin North Am. 2015;99(3):521-534.

29. Mascarenhas P, Gapski R, Al-Shammari K, Wang $\mathrm{H}-\mathrm{L}$. Influence of sex hormones on the periodontium. $J$ Clin Periodontol. 2003;30(8):671-681.

30. Reinhardt RA, Payne JB, Maze CA, Patil KD, Gallagher SJ, Mattson JS. Influence of estrogen and osteopenia/osteoporosis on clinical periodontitis in postmenopausal women. J Periodontol. 1999;70(8):823-828.

31. Friedlander AH. The physiology, medical management and oral implications of menopause. J Am Dent Assoc. 2002;133(1):73-81.

32. Krejci CB, Bissada NF. Women's health issues and their relationship to periodontitis. J Am Dent Assoc. 2002;133(3):323-329.

33. Famili P, Cauley J, Suzuki JB, Weyant R. Longitudinal study of periodontal disease and edentulism with rates of bone loss in older women. $J$ Periodontol. 2005;76(1):11-15.

34. Fleiss JL, Park MH, Chilton NW, Alman JE, Feldman RS, Chauncey HH. Representativeness of the "Ramfjord teeth" for epidemiologic studies of gingivitis and periodontitis. Community Dent Oral Epidemiol. 1987;15(4):221-224.

35. Cassol-Spanemberg J, Campillo E, Jané-Salas E, Lopez Lopez J. Burning Mouth Syndrome: Update. Oral Health Dent Manag. 2014;13:418-424. doi:10.12974/2311-8695.2014.02.01.2

36. Charleston L 4th. Burning mouth syndrome: a review of recent literature. Curr Pain Headache Rep. 2013;17(6):336.
37. Gardner A, Carpenter G, So P-W. Salivary Metabolomics: From Diagnostic Biomarker Discovery to Investigating Biological Function. Metabolites. 2020;10(2):47.

38. Akalin FA, Baltacioğlu E, Alver A, Karabulut E. Lipid peroxidation levels and total oxidant status in serum, saliva and gingival crevicular fluid in patients with chronic periodontitis. $J$ Clin Periodontol. 2007;34(7):558-565.

39. Tsai CC, Chen HS, Chen SL, et al. Lipid peroxidation: a possible role in the induction and progression of chronic periodontitis. J Periodontal Res. 2005;40(5):378-384. doi:10.1111/j.16000765.2005.00818.x

40. Konopka T, Król K, Kopeć W, Gerber H. Total antioxidant status and 8-hydroxy-2'-deoxyguanosine levels in gingival and peripheral blood of periodontitis patients. Arch Immunol Ther Exp (Warsz). 2007;55(6):417-422.

41. Reher VGS, Zenóbio EG, Costa FO, Reher P, Soares R V. Nitric oxide levels in saliva increase with severity of chronic periodontitis. $J$ Oral Sci. 2007;49(4):271-276.

42. Wei D, Zhang X-L, Wang Y-Z, Yang C-X, Chen G. Lipid peroxidation levels, total oxidant status and superoxide dismutase in serum, saliva and gingival crevicular fluid in chronic periodontitis patients before and after periodontal therapy. Aust Dent J. 2010;55(1):70-78.

43. Güllü C, Ozmeric N, Tokman B, Elgün S, Balos K. Effectiveness of scaling and root planing versus modified Widman flap on nitric oxide synthase and arginase activity in patients with chronic periodontitis. J Periodontal Res. 2005;40(2):168-175.

44. Batista AC, Silva TA, Chun JH, Lara VS. Nitric oxide synthesis and severity of human periodontal disease. Oral Dis. 2002;8(5):254-260.

45. Rüdin HJ, Overdiek HF, Rateitschak KH. Correlation between sulcus fluid rate and clinical and histological inflammation of the marginal gingiva. Helv Odontol Acta. 1970;14(1):21-26.

46. Hou LT, Liu CM, Rossomando EF. Crevicular interleukin-1 beta in moderate and severe periodontitis patients and the effect of phase I periodontal treatment. J Clin Periodontol. 1995;22(2):162-167.

47. Guentsch A, Preshaw PM, Bremer-Streck S, Klinger G, Glockmann E, Sigusch BW. Lipid peroxidation and antioxidant activity in saliva of 
periodontitis patients: effect of smoking and periodontal treatment. Clin Oral Investig. 2008;12(4):345-352.

48. Jin L, Söder B, Corbet EF. Interleukin-8 and granulocyte elastase in gingival crevicular fluid in relation to periodontopathogens in untreated adult periodontitis. J Periodontol. 2000;71(6):929-939.

49. Lamster IB, Oshrain RL, Gordon JM. Enzyme activity in human gingival crevicular fluid: considerations in data reporting based on analysis of individual crevicular sites. $J$ Clin Periodontol. 1986;13(8):799-804.

50. Smith QT, Au GS, Freese PL, Osborn JB, Stoltenberg JL. Five parameters of gingival crevicular fluid from eight surfaces in periodontal health and disease. J Periodontal Res. 1992;27(5):466-475.

51. Norderyd OM, Grossi SG, Machtei EE, et al. Periodontal status of women taking postmenopausal estrogen supplementation. J Periodontol. 1993;64(10):957-962. doi:10.1902/jop.1993.64.10.957

52. Tezal M, Wactawski-Wende J, Grossi SG, Ho AW, Dunford R, Genco RJ. The relationship between bone mineral density and periodontitis in postmenopausal women. J Periodontol. 2000;71(9):1492-1498.

53. Geurs NC, Lewis CE, Jeffcoat MK. Osteoporosis and periodontal disease progression. Periodontol 2000. 2003;32:105-110.

54. Mariotti A, Mawhinney M. Endocrinology of sex steroid hormones and cell dynamics in the periodontium. Periodontol 2000. 2013;61(1):69-88.

55. Thompson IO, van der Bijl $P$, van Wyk CW, van Eyk AD. A comparative light-microscopic, electronmicroscopic and chemical study of human vaginal and buccal epithelium. Arch Oral Biol. 2001;46(12):10911098.

56. Page RC. The pathobiology of periodontal diseases may affect systemic diseases: inversion of a paradigm. Ann Periodontol. 1998;3(1):108-120.

57. Klemetti E, Vainio P, Lassila V, Alhava E. Cortical bone mineral density in the mandible and osteoporosis status in postmenopausal women. Scand J Dent Res.
1993;101(4):219-223.

58. Kobayashi M, Matsumoto C, Hirata M, Tominari T, Inada M, Miyaura $\mathrm{C}$. The correlation between postmenopausal osteoporosis and inflammatory periodontitis regarding bone loss in experimental models. Exp Anim. 2012;61(2):183-187.

59. Baltacioğlu E, Akalin FA, Alver A, Balaban F, Unsal M, Karabulut E. Total antioxidant capacity and superoxide dismutase activity levels in serum and gingival crevicular fluid in post-menopausal women with chronic periodontitis. $J$ Clin Periodontol. 2006;33(6):385-392.

60. De A. A Comparative Study of periodontal status among pre-menopausal and post-menopausal women. Published online March 1, 2020.

61. Wulandari P, Masulili SLC, Kusdhany LS, Tadjoedin FM, Puspitadewi SR, Baziad A. Differences in Periodontal Severity Between Perimenopausal and Postmenopausal Women with Chronic Periodontitis.

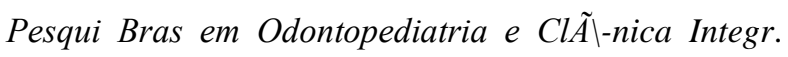
2019;19.

http://www.scielo.br/scielo.php?script=sci_arttext\&pid $=\mathrm{S} 1983-46322019000100431 \& \mathrm{nrm}=$ iso

62. Alves RC, Félix SA, Rodriguez-Archilla A, Oliveira P, Brito J, Dos Santos JM. Relationship between menopause and periodontal disease: a crosssectional study in a Portuguese population. Int J Clin Exp Med. 2015;8(7):11412-11419.

63. Prasanna JS, Sumadhura C, Karunakar P. A Comparative Analysis of Pre- and Postmenopausal Females with Periodontitis and Its Response to a Non Invasive Clinical Approach. $J$ menopausal Med. 2017;23(3):202-209.

64. Subbiah MT, Kessel B, Agrawal M, Rajan R, Abplanalp W, Rymaszewski Z. Antioxidant potential of specific estrogens on lipid peroxidation. J Clin Endocrinol Metab. 1993;77(4):1095-1097.

65. Sugioka K, Shimosegawa Y, Nakano M. Estrogens as natural antioxidants of membrane phospholipid peroxidation. FEBS Lett. 1987;210(1):37-39. 